\title{
O FILME AS SUFRAGISTAS E AS TRANSFORMAÇÕES NOS MODOS DE VIDA PELA MILITÂNCIA POLÍTICA: DESLOCAMENTOS SUBJETIVOS, SACRIFÍCIO DO CORPO E AFINIDADES FEMINISTAS
}

\author{
The Suffragettes film and the transformations in the \\ way of life by the political militancy: subjective \\ displacements, sacrifice of body and feminist \\ affinities
}

Priscila Piazentini Vieira*

\begin{abstract}
RESUMO
Esta comunicação discute o filme As Sufragistas, lançado em 2015 e dirigido por Sarah Gavron, a partir dos seguintes temas: o jogo que as sufragistas praticam com os direitos, tendo como principal objetivo aprovar o voto das mulheres na Inglaterra no início do século XX; as transformações subjetivas pelas quais as mulheres passam ao entrarem para a militância sufragista, prestando atenção nas suas relações com os maridos, os patrões e os filhos. O texto também levanta discussões sobre o sacrifício do corpo das mulheres nas fábricas, mas também em uma militância política permeada por uma ética que deve ser explicitada não somente por palavras, mas por ações e pelo emprego do corpo como a expressão da verdade. Também será abordado o destaque que o filme reserva para as afinidades feministas entre as personagens.
\end{abstract}

Palavras chave: As Sufragistas, afinidades feministas, transformações subjetivas

* Professora do Departamento de História da UFPR. Áreas: História Contemporânea e Teoria da História 


\begin{abstract}
In this this paper I discuss the film Suffragette, released in 2015 and directed by Sarah Gavron, from the following themes: the game that Suffragettes practice with the rights, for the main purpose of approving women's vote in England in the early twentieth century; subjective transformations in women that join to suffragette militancy, detaching the relations with their husbands, bosses and children. The text also presents discussions about the sacrifice of women's body in factories, in a political militancy pervaded by an ethic that must be evident not only by words, but also by actions and by use of the body as the expression of truth. In addition, the paper approaches the emphasis given by the film to the feminist affinities among the characters.
\end{abstract}

Keywords: Suffragette, feminist affinities, subjective transformations

"Imaginar que seria possível existir uma outra forma de viver essa vida". ${ }^{1}$ Essa é a resposta elaborada por Maud Watts (Carey Mulligan), personagem principal do filme As Sufragistas ${ }^{2}$, quando perguntada sobre o significado que a conquista do voto teria para ela. Ao depor no Parlamento sobre as condições do trabalho feminino nas lavanderias inglesas do começo do século XX, Maud revela que apesar das mulheres trabalharem mais que os homens, elas ganhavam um salário menor do que o deles e sofriam mais com os problemas de saúde. Eles faziam mais entregas de encomendas nas ruas, o que lhes garantia ar fresco e menos doenças nos pulmões.

A conquista do voto feminino e a igualdade de salários dariam às mulheres um novo modo de viver? O filme não nos dá elementos para responder a essa questão, mas mostra como a entrada na militância feminista e a participação nas lutas que levaram à aprovação do voto na Inglaterra, em 1928, transformaram drasticamente a vida de uma trabalhadora, dentro e fora da fábrica.

A proposta do presente artigo, portanto, é acompanhar a narrativa construída sobre as sufragistas inglesas pela linguagem cinematográfica, inspirando-me em reflexões realizadas por Michel

1 GAVRON, Sarah. As Sufragistas. Reino Unido: Universal Pictures, 2015, 22:33. (106 min). Colorido. Título original: Suffragette.

2 Idem. 
Foucault e pelos estudos feministas. Nesse sentido, considero a especificidade da linguagem cinematográfica, entendendo-a também como um discurso sobre o passado, que nunca se confunde com ele. Mesmo reconhecendo a importância das inúmeras discussões acerca da análise do documento e da narrativa histórica ${ }^{3}$, recorro à fala da personagem principal do romance $O$ conto da Aia, escrito por Margaret Atwood, para nos alertar que o filme, assim como qualquer texto, não é o reflexo do passado tal qual ele aconteceu:

Tento me lembrar se o passado era exatamente assim. Não tenho certeza, agora. Sei que continha essas coisas, mas de algum modo a mistura é diferente. Um filme sobre o passado não é igual ao passado. ${ }^{4}$

O filme, dirigido por Sarah Gavron e lançado em 2015, conta a história do movimento sufragista inglês a partir de diversas mulheres, reportando-se às participações da grande líder intelectual, Emmeline Pankhurst (Meryl Streep); de uma mulher de elite e esposa de um deputado, Alice Haughton (Romola Garai); de uma profissional liberal do ramo farmacêutico, Edith Ellyn (Helena Bonham Carter).

Mas é a vida da operária Maud Watts que a narrativa cinematográfica acompanha mais de perto. Ela trabalha na lavanderia do patrão Mr. Taylor (Geoff Bell) em meio período desde os $7 \operatorname{anos}^{5}$ e, em período integral, desde os 12. Sua mãe também trabalhou no mesmo local. Ela levava a filha desde muito cedo para a fábrica, e

3 Ver: FOUCAULT, Michel. A ordem do discurso. Aula inaugural no Collège de France, pronunciada em 2 de dezembro de 1970. Trad. Laura Fraga de Almeida Sampaio. São Paulo: Edições Loyola, 1996; "Introdução". A arqueologia do saber. 7. Ed. Trad. Luiz Felipe Baeta Neves. Rio de Janeiro: Forense Universitária, 2008. WHITE, Hayden. Trópicos do Discurso. Ensaios sobre a crítica da cultura. Trad. Alípio Correia de Franca Neto. São Paulo: Editora da Universidade de São Paulo, 1994. p.282.

4 ATWOOD, Margaret. O conto da Aia. Trad. Ana Deiró. Rio de Janeiro: Rocco, 2006,

5 Sobre o trabalho infantil nas fábricas ver: Rago. Do cabaré ao lar: a utopia da sociedade disciplinar e a resistência anarquista (1890-1930). 4a Ed. São Paulo: Paz e Terra, 2014, pp.156-213. 
costumava amarrá-la ao seu próprio corpo para cuidá-la e trabalhar ao mesmo tempo, devido à exigência de voltar rapidamente à lavanderia logo após o parto, para manter o emprego. Morreu quando Maud tinha 4 anos, queimada por uma caldeira que despencou.

$\mathrm{Na}$ lavanderia, Maud passava e engomava as roupas de maneira perfeita, tanto que sua ascensão dentro do ambiente fabril era digna de admiração: aos 17 anos já era a chefe da lavanderia e, aos 20, torna-se a líder. Agora, aos 24 anos, apesar do trabalho duro e impecável $^{6}$, era vítima de olhares desconfiados tanto dos trabalhadores quanto das trabalhadoras, que sabiam das "regalias" e preferências que ela possuía com o patrão, certamente por outras ligações que ultrapassavam o âmbito de sua função dentro da lavanderia, mas não a rotina das fábricas. As mulheres, além de conviverem com as péssimas condições de trabalho, semelhante ou até mesmo pior que as dos homens, eram vítimas de corriqueiros abusos sexuais.

Maud era casada com um operário (Ben Whishaw), que trabalhava na mesma lavanderia, e com o qual tinha um filho (Adam Michael Dodd). Sua jornada começava cedo $^{7}$ : acordava, preparava o café da família, vestia o filho e deixava-o aos cuidados de uma vizinha, enquanto trabalhava durante todo o dia. Voltava à noite, cuidava do filho, fazia o jantar da família, lavava a roupa, agora dentro de casa. Era a última a se deitar, depois do filho e do marido. A sua dupla jornada pode ser percebida em imagens que o filme repete em muitas ocasiões: os varais repletos de roupas lavadas nas ruas do bairro e dentro da casa em que morava. ${ }^{8}$ As roupas, assim, acompanhavam as mulheres no trabalho e no ambiente doméstico. No começo do mês, ela entregava todo o seu salário ao marido, pois cabia a ele cuidar das finanças da casa. ${ }^{9}$

As coisas começam a mudar quando ela repara no tratamento hostil do patrão reservado a uma das operárias da lavandeira. ${ }^{10} \operatorname{Logo}$

6 Maud Watts conta toda a sua história no depoimento que dá ao Parlamento Inglês. GAVRON, Sarah. op.cit., 20:00.

7 Idem, 6:00.

8 Idem, 5:14.

9 Idem, 10:35.

10 Idem, 7:30; 16:35. 
descobre que se trata de Violet Miller (Anne-Marie Duff), uma sufragista que iria depor no Parlamento inglês, para contar das péssimas condições de trabalho que enfrentava e para ajudar na aprovação do voto feminino.

Alice Haughton, esposa do deputado, que fazia caridades nas fábricas e costumava discursar em suas entradas sobre a importância das mulheres conseguirem ganhar o mesmo salário que os homens e sobre a luta pela aprovação do voto feminino, daria a ela o devido suporte. $\mathrm{O}$ discurso de Alice era sempre recebido com desaprovação por muitas trabalhadoras, pelo patrão e pelos trabalhadores. Os dois últimos, ainda, perguntavam-se se em algum dia Alice havia trabalhado $^{11}$, mostrando como a hostilidade diante das mulheres militantes de elite os unia, apesar da luta de classes.

Maud, vendo as ridicularizações sofridas pela companheira de trabalho por ir depor, resolve acompanhá-la. Esta atitude será decisiva, pois Violet chega no Parlamento desfigurada pelas agressões do marido bêbado, e cede seu direito de depor a Maud, que surpreende a todos pelas palavras diretas e sem rodeios sobre a sua péssima condição de vida no trabalho. ${ }^{12}$ A maioria dos parlamentares, no entanto, não se simpatiza pela causa das mulheres, pois, mesmo escutando todo o depoimento, não encontram evidências contundentes para aprovar o voto feminino. ${ }^{13}$

Maud já tinha se encontrado com Violet em um outro momento, fora da fábrica, em uma cena que inicia o filme. Intimada pelo patrão a fazer uma entrega na cidade, ela pega o ônibus e caminha pelas ruas de Londres à procura do local. Enquanto isso, pára diante de uma loja de roupas e acessórios, com a vitrine composta por três manequins: a mãe e os seus dois filhos. ${ }^{14}$ Maud observa admirada aquela família, talvez desejando alcançar aquele padrão material ou lembrando-se de como era feliz com a sua família. Toda essa paz encenada no meio familiar é violentamente estilhaçada, junto com as vitrines de vidro, por uma pedra jogada pelas sufragistas, em seus atos políticos de ação direta de desobediência civil. 
A cena é fundamental para indicar que a luta das militantes pela conquista do voto feminino transformaria outras convenções, além das leis. Era o próprio modelo de família nuclear burguês, que também predominava entre os pobres, que seria despedaçado. Lembro, ainda, que as pedras lançadas pelas sufragistas às vitrines das lojas caras de departamento, inacessíveis para as trabalhadoras, saem debaixo das cobertas de carrinhos de bebês. A substituição dos bebês pelas pedras integra uma cena metafórica que demonstra como a luta pelo voto também dizia respeito às mudanças exercidas nos próprios modos de vida das famílias.

É Michelle Perrot, no texto "A família triunfante", que compõe o quarto volume da História da vida privada ${ }^{15}$, quem mostra como as relações entre o público e o privado estavam no centro de toda a teoria política depois da Revolução Francesa. Era preciso, nesse momento, organizar os "interesses privados". ${ }^{16}$ A família é compreendida como célula base e o doméstico constitui uma instância reguladora fundamental. De Hegel a Kant, dos conservadores aos liberais, a família é considerada o fundamento da sociedade civil. O modelo que impera é o do casamento monogâmico e a chefia era exercida pelo pai. A esfera pública, que englobava o Estado, a ciência e o trabalho, estaria destinada ao homem, enquanto a privada, composta pelo lar, à mulher, à esposa, e aos cuidados com os filhos e o marido.

Esse ambiente privado, como defendia Kant, devia estar sempre submetido ao pai, "o único capaz de refrear os instintos, de domar a mulher". ${ }^{17}$ Nesse sentido, a guerra doméstica constituía uma ameaça constante, ainda mais se a mulher escapasse ao seu ideal de domesticidade e submissão para se tornar uma rebelde ou uma revolucionária. Daí o incômodo muito grande que as sufragistas ainda causavam na sociedade inglesa do começo do século XX, entre 1912 e 1913. A entrada de Maud para a militância desagradará o marido, o patrão, as autoridades policiais e a vizinhança vigilante dos bons

15 PERROT, Michelle. "A família triunfante". In: História da vida privada 4. Da Revolução Francesa à Primeira Guerra. Trad. Denise Bottmann. São Paulo: Companhia das Letras, 2009, pp.79-90.

16 Idem, p.79.

17 Idem, p.81. 
costumes. O marido critica a repetição do comportamento da mulher, ao ser presa pela segunda vez, dizendo: "Você é uma mãe. Você é uma esposa. Minha esposa. É isso que você deve ser". Maud responde: "Eu não sou só isso agora". Depois desse diálogo, é expulsa de casa pelo marido. ${ }^{18}$

Esse estranhamento dos homens diante da atuação política das suas mulheres não acontecia somente entre os integrantes das classes menos favorecidas. Na primeira prisão das sufragistas, o deputado paga a fiança somente à sua mulher, mesmo diante das súplicas de sua esposa para que libertasse a todas as mulheres. Alice responde ao marido, argumentando que o dinheiro era dela. Ela tinha, dessa maneira, mais privilégios que as trabalhadoras, mas não tantos quanto os homens de sua classe, como expressa o diálogo: "Ela diz: É meu dinheiro. Ele responde: Mas você é minha esposa. E você vai agir como uma. Eu não levei você a sério Alice, mas isso é uma vergonha". ${ }^{19}$ Maud assiste à cena e, mesmo com a diferença de classe, resta essa obediência forçada aos maridos que as une. É, finalmente, o marido de Ellyn, que liberta a todas. Visto pelos policiais como um anarquista, ele nunca enxergará a atividade política da mulher como um contraste em relação ao seu papel de esposa. Na saída, Watts não tem ninguém para recebê-la, diferentemente da mulher de elite e da profissional liberal. ${ }^{20}$

A aprovação do voto feminino, dessa maneira, esfacelaria essa separação entre o público e o privado, que concebia o poder político como um assunto de homens para homens. A grande preocupação dos tradicionalistas era a família. Suas críticas englobavam o afrouxamento dos costumes, a distorção dos papeis sexuais e o efeminamento. ${ }^{21}$ Perrot ainda lembra que as famílias desfeitas e as mulheres esquecidas de seus deveres eram os bodes expiatórios usuais das derrotas militares e das turbulências sociais. Maud é um exemplo claro dessa situação, pois terá que lidar com a culpa de ter sido separada do filho pelo marido devido à sua entrada

18 GAVRON, Sarah. op.cit., 48:40.

19 Idem, 31:20.

20 Idem, 37:40.

21 PERROT, Michelle. op.cit., p.84. 
na militância sufragista, subvertendo o papel convencional de mãe e de esposa.

Essa insistência no modelo tradicional de família também era tema entre os socialistas que, segundo Perrot, eram unânimes em criticar a família de sua época, mas eram raros os que pensavam em sua total eliminação. Ela escreve: "Igualmente raros são os que pretendem uma subversão dos papeis sexuais, tão profunda é a crença numa desigualdade natural entre homens e mulheres". ${ }^{22}$ Entre os partidários de uma liberdade irrestrita estavam: o socialista Charles Fourier, o saint-simoniano Prosper Enfantin, a feminista Claire Démar e alguns comunistas de 1840, como Théodore Dézamy.

Perrot mostra como Fourier representava um radicalismo bastante excepcional. Para ele, a chave do progresso residia na emancipação feminina. ${ }^{23} \mathrm{O}$ radicalismo de Fourier em relação à sexualidade assustou muitos dos seus discípulos, como Victor Considérant e as suas seguidoras, como Zoé Gatti de Gamond. Muitos saint-simonianos, por exemplo, lutavam pela manutenção do casamento monogâmico, e o anarquista Proudhon defendia a desigualdade irredutível dos sexos, fundada na natureza, afirmando a submissão necessária das mulheres ao casamento indissolúvel e patriarcal. ${ }^{24}$ Não havia nada, nem mesmo entre os revolucionários de esquerda, portanto, que garantisse a liberdade dos costumes, mesmo entre a classe operária e popular, para a qual a economia e a moral familiar eram constitutivas da consciência de classe. ${ }^{25}$

Mesmo entre os socialistas mais radicais, Perrot observa um movimento importante nas suas concepções de transformação social. Os que compunham a primeira metade do século XIX acreditavam numa revolução pela base e pela prática. Daí a existência das comunidades exemplares. Mas, com o blanquismo e o marxismo:

(...) o problema da tomada de poder se coloca de outra maneira: a revolução política, pelo alto, é um prelúdio

\footnotetext{
22 Idem, p.86.

23 Idem, p.87.

24 Idem, p.88.

25 Idem.
} 
indispensável da revolução econômica pelo Estado. Na análise social, o modo de produção vem ocupar o lugar da família, e os costumes ficam relegados ao cimo da superestrutura. $^{26}$

A esquerda revolucionária, então, conclui Perrot:

(...) considera a revolução socialista dos meios de produção a condição necessária - se não suficiente - para o restabelecimento da igualdade. As mulheres são convidadas a subordinar suas reivindicações à luta de classes, e a luta entre os sexos é tida como um derivativo. O feminismo, agora, é condenado a ser burguês, quase por essência: é o início de um longo mal-entendido". ${ }^{27}$

Por isso, podemos entender o porquê de no filme as sufragistas não receberem nenhum apoio de outro grupo revolucionário, nem mesmo dos operários sindicalizados, mesmo que a militância das mulheres tenha surgido juntamente com os movimentos cartista e abolicionista. ${ }^{28} \mathrm{O}$ marido de Maud não parece compor nenhuma militância e sua postura contrária à luta pelo voto feminino é marcante para as transformações na vida da mulher.

O único marido (Finbar Lynch) que apoia a companheira é o de Edith Ellyn, a farmacêutica, pois integrava a Men's League que, assim como a sua versão norte-americana, apoiava a luta das mulheres pela conquista de seus direitos políticos. Mesmo ele, que dá suporte para as ações das mulheres, proíbe Edith de participar do combate final das sufragistas diante do Rei, trancando-a em um

26 Idem, p.89.

27 Idem.

28 Para esse tema ver: ABREU, Zina. "Luta das mulheres pelo direito do voto. Movimentos sufragistas na Grã-Bretanha e nos Estados Unidos”. Arquipélago História, n. VI, 2002. Apud: HOEVELER, Rejane Carolina. "'Suffragette': lições do passado, questões do presente”. In: http://blogjunho.com.br/suffragette-licoes-do-passado-questoes-do-presente/. Acesso em: $13 / 02 / 2017$. 
depósito de sua casa. ${ }^{29}$ A justificativa dada por ele para esse comportamento drástico revela a preocupação com a saúde frágil da esposa depois das inúmeras prisões pelas quais ela havia passado, temendo pela sua morte.

No filme, ele é uma das vozes que coloca em dúvida o prosseguimento político das ações de intervenções radicais das sufragistas, como as explosões das linhas de comunicação e da casa em construção do Primeiro Ministro. Ele indaga a esposa: "E se você se explodir com uma dessas coisas malditas? O que acontece com a sua maldita causa?". ${ }^{30}$ Ressoam as seguintes perguntas ao longo de vários momentos do filme: Qual é o limite da militância? Vale morrer por uma causa? Impedida de participar somente desse ato, Edith continuou a lutar, talvez servindo-lhe bem a seguinte frase de Virginia Woolf em Um teto todo $\mathrm{seu}^{31}$ : "Tranque suas bibliotecas, se quiser, mas não há portão, nem fechadura, nem trinco que você consiga colocar na liberdade de minha mente". ${ }^{32}$

Para Foucault, e refiro-me aqui ao seu último curso dado em 1984, A coragem da verdade ${ }^{33}$, a revolução no mundo europeu moderno não foi simplesmente um projeto político, mas foi também uma forma de vida. Chamou-se "militantismo",34 a maneira pela qual se definiu, caracterizou-se, organizou-se a vida como uma atividade revolucionária, ou elaborou-se a atividade revolucionária como vida consagrada, total ou parcialmente, à Revolução. ${ }^{35} \mathrm{~A}$ maneira de ser militante que Foucault destaca é o militantismo como testemunha pela vida, sob a forma de um estilo de existência, que está em ruptura com as convenções, os hábitos e os valores da sociedade. O militante deve manifestar diretamente, pela sua forma visível, pela sua prática

29 GAVRON, Sarah. op.cit., 1:25:35.

30 Idem, 1:12:25. Livro, 1990.

31 WOOLF, Virginia. Um teto todo seu. Trad. Vera Ribeiro. São Paulo: Círculo do

32 Idem, p.94.

33 FOUCAULT, Michel. "Aula de 29 de fevereiro de 1984 - Segunda hora". A coragem da verdade. O governo de si e dos outros II. Curso dado no Collège de France. (1983-1984). Trad. Eduardo Brandão. São Paulo: Martins Fontes, 2011.

34 Idem, p.161.

35 Para essa discussão, ver tais reflexões em: VIEIRA, Priscila Piazentini. A coragem da verdade e a ética do intelectual em Michel Foucault. São Paulo: Intermeios; Fapesp, 2015, p.90. 
constante e sua existência imediata, a possibilidade concreta e o valor evidente de uma vida outra, que é a vida verdadeira. ${ }^{36}$

Esse tema da transformação radical da vida pela militância é tratado no filme pela entrada de Maud no movimento sufragista. Depois do seu depoimento ao Parlamento Inglês, ela é acolhida pelas feministas, mesmo que a líder Pankhurst inspire-as sempre com o lema: "São atos, não palavras, que nos darão o voto", frase que é repetida pela profissional liberal Edith ${ }^{37}$ e escrita na parede da prisão por Maud. ${ }^{38}$

Desde o convite feito pela amiga Violet para entrar no grupo até à sua participação ativa no movimento, Maud passou por duas detenções, foi expulsa de casa pelo marido, foi demitida pelo patrão e perdeu o filho, depois do marido colocá-lo para a adoção. Nesse período, o homem era o detentor da guarda dos filhos ${ }^{39}$ e, após intensa luta das feministas, em 1925 foram reconhecidos os direitos das mães sobre os seus filhos. Nenhuma das sufragistas sabia se a conquista do voto traria um novo modo de viver, mas a participação na militância provocou deslocamentos subjetivos fundamentais e dolorosos.

Maud já não se via mais somente como uma esposa ou uma mãe, mas também como uma militante, pronta para atuar de maneira radical pela sua causa. Em uma carta escrita ao inspetor de polícia, ela mostra como não se tratava apenas de um movimento para conseguir a aprovação do voto das mulheres, mas de transformar suas próprias vidas. Em meio às seguintes palavras, que são pronunciadas por Maud, desenrolam-se algumas cenas: a de Maud fazendo brincadeiras para o seu filho na rua, embaixo de chuva $^{40}$, pois seu marido não a deixava entrar em casa, e uma outra cena na qual Edith Ellyn a chama para dançar, com a frase sugestiva: "Você tem que participar, se quer mudar o modo como o mundo funciona" ${ }^{41}$ :

36 Idem, p.94.

37 GAVRON, Sarah. op.cit., 12:09.

38 Idem, 1:18:00.

39 Idem, 1:01:10.

40 Idem, 1:03:00.

41 Idem, 1:03:35. 
Você me disse que ninguém ouve garotas como eu. Bem, eu não posso aceitar mais isso. Toda a minha vida eu fui uma pessoa respeitável. Fiz o que os homens disseram. Eu compreendo as coisas de outro jeito agora. Eu não valho mais, nem menos que você. A senhora Pankhurst disse uma vez que se os homens têm o direito de lutar pela sua liberdade então é direito das mulheres lutarem também. Se a lei diz que não posso ver meu filho, eu vou lutar para mudar a lei. Nós dois somos soldados de frente de uma forma ou de outra. Ambos lutando por uma causa. Eu não vou trair a minha causa. Você trairia a sua? Se você pensou que eu o faria, está enganado sobre $\operatorname{mim}^{42}$

A líder Pankhurst já havia alertado para os sacrifícios que as mulheres deveriam fazer para estarem na luta, afastando-se muitas vezes completamente da vida que uma vez tiveram. Ora, foi a falta de sucesso do movimento sufragista durante cinquenta anos, sendo alvo de ridicularizações e reprovações da maioria, que levou as mulheres a adotarem medidas políticas radicais ${ }^{43}$, inspiradas na desobediência civil, de Henry Thoreau. ${ }^{44}$

A ação direta na quebra de vitrines de lojas comerciais e na explosão de propriedades privadas fazia parte, também, dos sacrifícios exigidos pela líder. O seu discurso, que ocupa apenas alguns minutos do filme ${ }^{45}$, mostrando novamente a preferência da diretora Sarah Gavron pela importância da ação das trabalhadoras para o movimento, defende que o descaso do governo deixou as sufragistas sem opção. Restou apenas a luta pela intervenção direta.

42 Idem, 1:01:45.

43 O título original do filme é Suffragette. A tradução brasileira perde as transformações nos modos de militar e as divergências entre as correntes da luta pela aprovação do voto. Sobre as diferenças entre as suffragists, consideradas mais tradicionais e que adotavam como pauta causas e meios de ação pelas vias institucionais, e as suffragettes, com uma radicalidade maior e ações diretas ver: HOEVELER, Rejane Carolina. "Suffragette: lições do passado, questões do presente", em: http://blogjunho.com.br/suffragette-licoes-do-passado-questoes-do-presente/. Acesso em: 13/02/2017.

44 THOREAU, Henry David. A desobediência civil. Trad. José Geraldo Couto. São Paulo: Penguin Classics Companhia das Letras, 2012.

45 GAVRON, Sarah. op.cit., 44:10-46:20. 
Mais tarde, é Maud quem falará ao superintendente da polícia inglesa (Brendam Gleeson) que os homens só entendem a linguagem da violência e da guerra, depois deste indagar-lhe sobre o fato de quase a explosão ter atingido a empregada da casa do Primeiro Ministro:

\begin{abstract}
Superintendente: $\mathrm{O}$ que seria da sua causa se ela tivesse morrido? A violência não faz discernimentos. Leva os inocentes e os culpados. O que dá a você o direito de por a vida das mulheres em risco? Maud Watts: O que dá a você o direito de ficar no meio das manifestações e não fazer nada? Superintendente: Eu sou a lei. Maud Watts: A lei não significa nada para mim. Não participei de sua feitura. Nós quebramos vitrines. Nós quebramos coisas, porque guerra é a única linguagem que os homens compreendem. Porque vocês nos traíram e nos bateram até que não sobrasse nada. ${ }^{46}$
\end{abstract}

Assim como em muitos momentos do filme, a validade da lei é colocada em questão por Maud Watts, mostrando que o direito, mais do que sinônimo de neutralidade, justiça e igualdade, não tinha significado algum para ela, associando-o à guerra e à violência. Emergem algumas indagações no filme: O que é mais importante? A violência cotidiana pela qual as mulheres passam ou o valor das vitrines das lojas e das propriedades privadas? A própria líder do movimento já havia afirmado em seu discurso: "Se devemos ser presas para conseguirmos o voto deixe que sejam as janelas do governo e não nossos corpos que quebrem".

Os corpos das mulheres, entretanto, "quebraram". Para lutar pela conquista do voto, além da transformação na vida profissional e familiar, era preciso lutar pela sobrevivência das forças vitais do corpo. As constantes prisões, que pela primeira vez foram realizadas com a ajuda das recentes câmeras de vigilâncias portáteis ${ }^{48}$, 
reservavam aos corpos das mulheres testes extremamente arriscados que as deixavam entre a vida e a morte. As intensas greves de fome por não serem reconhecidas como presas políticas, seguindo as ordens da líder, eram os exemplos claros dessa situação. Maud protagoniza uma das cenas mais fortes do filme: a alimentação forçada por meio de um tubo nasal. ${ }^{49}$ A cada prisão, a saúde das mulheres se deteriorava.

O combate final das sufragistas tinha como objetivo divulgar a causa em um evento de corrida de cavalo no qual estariam presentes a imprensa, milhares de pessoas e o Rei da Inglaterra. Além de visibilidade, elas também procuravam pelo perdão do Rei ao crime cometido pela líder Pankhurst, presa por reivindicar a autoria da explosão da casa do Primeiro Ministro. Uma segunda detenção poderia causar a sua morte, pois, comentavam as militantes, sua saúde certamente não aguentaria.

Maud e Emily (Natalie Press) seguem para a corrida, onde acontecerá um acidente chocante: Emily, disposta a colocar em prática o seu objetivo e lutar pela causa correndo qualquer risco, não admitia sair do evento sem cumprir a sua missão. Então, lança-se na frente do cavalo do Rei no meio da corrida com a bandeira do movimento das sufragistas. Antes do choque fatal, Emily reproduz a frase da líder para Maud: "Nunca se renda. Nunca desista da luta". ${ }^{0}$

A perda da vida por uma causa, que muitos personagens do filme temiam, aconteceu. O sacrifício não foi em vão. A morte foi registrada pela imprensa e todos os presentes tomaram contato com as reivindicações das sufragistas. A partir daí, o funeral de Emily atraiu atenção à causa e tornou possível uma passeata com um grande número de pessoas defendendo a conquista do direito ao voto pelas mulheres. Ele foi aprovado na Inglaterra parcialmente em 1918 para as mulheres com mais de 30 anos e, o sufrágio universal, veio em 1928.

A vida de Maud fora da militância e dentro das convenções também era extenuante para o seu corpo. $\mathrm{O}$ trabalho na lavanderia 
havia queimado o seu braço ${ }^{51}$, as tosses já surgiam, causadas pelas fumaças das máquinas que eram inaladas diariamente. A vestimenta feminina ainda utilizada no período debaixo dos vestidos era o corselet, que comprimia a sua cintura fortemente. Por fim, ainda tinham os abusos sexuais sofridos na lavanderia. Tais abusos são sempre sugeridos no filme, nunca claramente explicitados, pelo menos em relação à Maud. Há uma cena em que ela flagra o patrão abusando da filha de Violet. ${ }^{52}$ Ao ser interrompido, o patrão fica furioso e diz a Maud que a menina o fazia lembrar-se dela. Em muitos trechos do filme, ficam implícitos os abusos. Até o marido dela sabia, mas não expressava nenhum tipo de revolta.

A não explicitação dos abusos sexuais pelo filme é uma maneira da linguagem cinematográfica mostrar como essa prática no ambiente de trabalho era corriqueira e socialmente aceita. Todos sabiam, mas ninguém se incomodava. Os abusos eram naturalizados e compunham a ordem das convenções sociais. Eram, portanto, invisíveis. Outra cena do filme é emblemática para essa questão. Depois de entrar para o movimento sufragista, ser expulsa de casa e acolhida pelas militantes, ela encara as investidas do patrão de outra maneira. ${ }^{53}$

Voltando a trabalhar depois de uma detenção, ela cumpre sua função de trabalho normal: passando as roupas com o ferro quente. Com a sua foto publicada no jornal como uma das sufragistas, o patrão a despede. Mas afirma, em um tom sarcástico, que era uma bela foto, e até a colocaria na parede de sua casa. Enquanto o diálogo prossegue, o patrão passa a mão pelas costas de Maud, e podemos imaginar que essa aproximação a faz relembrar das várias vezes em que foi vítima de violência e não pôde reagir. Ou até mesmo a própria mãe lhe venha à mente. Como nunca havia conhecido o pai, o filme abre a possibilidade para desconfiarmos até se o patrão não seria o seu pai.

Agora, já transformada pela militância, Maud não aguenta as investidas e surpreende o patrão: queima-o com o ferro quente, 
diretamente nas mãos que passavam pelas suas costas. Essa cena simboliza uma inversão das convenções sociais dentro da lavanderia, por meio das queimaduras. Agora era o patrão a ser ferido, e não mais as trabalhadoras. Além disso, expressa uma transformação em sua atitude de obediência: ela já não era mais a trabalhadora submissa diante dos abusos naturalizados do patrão.

Essa força de Maud para combater o patrão e lutar para a conquista da aprovação do voto feminino foi possível, como bem mostra o filme, não somente pelo amor à causa política ou pela persistência de uma militante obstinada em traçar o seu destino, mas também por toda uma rede de solidariedade criada entre as sufragistas. É graças ao apoio constante das mulheres, principalmente de Violet Miller, acolhendo Maud depois que é expulsa de casa e após as suas saídas da prisão, fornecendo-lhe alimentação e segurança, que ela tem coragem para continuar. Mesmo antes da sua entrada para a militância, Edith Ellyn realizava consultas para o seu filho sem cobrar nenhuma quantia. ${ }^{54}$

Já Emily oferece-lhe uma inspiração para lutar, com o compartilhamento do livro Dreams ${ }^{55}$, de uma escritora feminista sulafricana, Olive Schreiner, de 1890. Na capa do livro, estavam as assinaturas de muitas sufragistas, que encontraram nas palavras da escritora uma inspiração para sonhar e conquistar a terra da liberdade. Após a morte de Emily, Maud lê um longo trecho do livro ${ }^{56}$, ajudando-a a retomar as suas forças, enquanto são intercaladas cenas de preparação da passeata que reuniu milhares de mulheres:

Uma mulher andarilha continua a buscar a terra da liberdade. Como vou chegar lá? A razão responde: Existe um caminho e somente ele. Através do caminho do trabalho, através das águas do sofrimento. A mulher, tendo descartado tudo em que ela antes acreditava, pergunta: O que devo fazer para alcançar essa terra que nenhuma jamais alcançou? Estou sozinha. Eu estou

54 Idem, 11:45

55 SCHREINER, Olive. Dreams. Oxford: Hard Press, 2006.

56 GAVRON, Sarah. op.cit., 1:35:15. 
completamente sozinha. E a razão disse a ela: Silêncio, o que ouço? Eu ouço os sons dos passos. Centenas deles, milhares e milhares e milhares vindo nessa direção. São os passos daquelas que a seguram. Mostre o caminho. ${ }^{57}$

O próximo nome a ser gravado na capa do livro, assim, seria o de Maud. Quem sabe até o da filha de Violet, que é retirada da fábrica por Maud ${ }^{58}$, afastando-a dos abusos de Mr. Taylor e levando-a para trabalhar na casa de Alice Haughton, a sufragista da elite, que a acolhe prontamente. É uma rede de solidariedade e afetividade, portanto, que é sempre reatualizada pelas suas integrantes. O que não elimina as diferenças de classe entre as mulheres, já que a filha de Violet é acolhida pela Sra. Haughton como uma empregada.

Leio essa rede de solidariedade entre as mulheres, dessa maneira, não pela aproximação entre elas por uma suposta identidade natural que as reuniriam em torno da figura universal da "mulher". Inspirando-me em Donna Haraway, em seu "Manifesto Ciborgue" lembro que: "Não existe nada no fato de ser 'mulher' que naturalmente una as mulheres". ${ }^{60}$ Pode-se, desse modo, pensar em uma rede de afinidades criada entre elas "não por sangue, mas por escolha". ${ }^{61}$

Haraway, assim como muitas outras feministas das décadas de 1980 e 1990, criticaram fortemente a criação da figura universal da "mulher" pelo feminismo, que produziu inúmeras exclusões, como expressa a seguinte passagem: "O que está em jogo, na conexão 'ocidental', é o fim do homem. Não é por acaso que, em nosso tempo, a 'mulher' se desintegra em 'mulheres'". ${ }^{62}$ Para não reproduzir uma lógica semelhante à da centralidade reservada ao "Homem" na cultura ocidental, ela defende outra forma de ação política entre as mulheres:

57 Idem, 1:38:00.

58 Idem, 1:33:50.

59 HARAWAY, Donna. "Manifesto ciborgue. Ciência, tecnologia e feminismosocialista no final do século XX". In: TADEU, Tomaz (org.). Antropologia do ciborgue: as vertigens do pós-humano (2a ed.). Belo Horizonte: Autêntica Editora, 2009, pp.34-118.

60 Idem, p.47.

61 Idem, p.46.

62 Idem, p.58. 
"Sua capacidade de ação não pode ter como base qualquer identificação supostamente natural: sua base é a coalizão consciente, a afinidade, o parentesco político". ${ }^{63}$

Escrevendo sobre a crise da identidade política em 1984, Haraway desejava que as reações da esquerda e do feminismo norteamericano não fossem construídas a partir de respostas que são dadas por meio das infindáveis cisões e das incessantes buscas por uma nova unidade essencial. Ela conclui:

(...) as fontes dessa crise de identidade política são incontáveis. A história recente de grande parte da esquerda e do feminismo estadunidense tem sido construída a partir das respostas a esse tipo de crise respostas que são dadas por meio de infindáveis cisões e de buscas por uma nova unidade essencial. Mas existe também o reconhecimento crescente de uma outra resposta: aquela que se dá por meio da coalizão - a afinidade em vez da identidade. ${ }^{64}$

O olhar da diretora Sarah Gavron sobre o movimento sufragista inglês, assim, sublinhou essas afinidades feministas, ainda fundamentais para a nossa atualidade.

RECEBIDO EM: 16/02/2017

APROVADO EM: 09/06/2017

63 Idem, p.49.

64 Idem, p.48. 